\title{
School-aged neurodevelopmental outcomes for children born extremely preterm
}

\author{
Lex W Doyle (D) , 2,3,4 Alicia Spittle, 2,5 Peter J Anderson, 2,6 \\ Jeanie Ling Yoong Cheong (D) 1,2
}

\begin{abstract}
'Neonatal Services, Royal Women's Hospital, Parkville, Victoria, Australia

${ }^{2}$ Victorian Infant Brain Studies (VIBeS), Murdoch Children's Research Institute, Parkville, Victoria, Australia

${ }^{3}$ Department of Obstetrics and Gynaecology, University of Melbourne, Parkville, Victoria, Australia

${ }^{4}$ Department of Paediatrics, University of Melbourne, Parkville, Victoria, Australia ${ }^{5}$ Department of Physiotherapy, University of Melbourne, Parkville, Victoria, Australia ${ }^{6}$ Psychological Sciences, Monash University, Melbourne, Victoria, Australia
\end{abstract}

\section{Correspondence to}

Professor Lex W Doyle, Obstetrics and Gynaecology, Royal Women's Hospital, Parkville, VIC 3052, Australia; Iwd@unimelb.edu.au

Received 20 January 2021 Revised 13 April 2021 Accepted 8 May 2021 Published Online First 25 May 2021

\section{Linked}

- http://dx.doi.org/10.1136/ archdischild-2021-321923

Check for updates

(c) Author(s) (or their employer(s)) 2021. No commercial re-use. See rights and permissions. Published by BMJ.

To cite: Doyle LW, Spittle A, Anderson PJ, et al.

Arch Dis Child

2021:106:834-838.

\section{ABSTRACT}

As survival rates for children born extremely preterm (EP, $<28$ weeks' gestation) have increased with advances in perinatal and neonatal care, their long-term functioning and quality of life assume more importance. Outcomes in early childhood provide some information, but outcomes at school-age are more informative of lifelong functioning. Children born EP at school-age have substantially higher rates of intellectual impairment, poorer executive, academic and motor function, more neurodevelopmental disability, and poorer health-related quality of life than do contemporaneous term-born controls. Because the rates of adverse outcomes remain unacceptably high, and particularly since some outcomes may be deteriorating rather than improving over time, new strategies to ameliorate these problems, targeting periods before, during and after birth, and throughout the lifespan, are a priority.

Survival rates for children born extremely preterm (EP; $<28$ weeks' gestation) have improved dramatically, from $<10 \%$ fifty years ago, before the advent of modern neonatal intensive care, to close to $90 \%$ for those offered intensive care today. ${ }^{1}$ Consequently, their long-term health and functioning assume increasing importance. Studies in the first few years after birth provide critical information on early development, but do not relate well to functioning at school-age and beyond ${ }^{2}$ because important outcomes such as general intelligence (IQ), executive function and motor co-ordination cannot be reliably assessed. Moreover, it is important to determine long-term outcomes to understand whether delays in early childhood evolve into long-term neurodevelopmental impairments, or the children ultimately improve and 'catch-up' with their peers.

Our aim in this article is to review data on important functional outcomes at school-age, including IQ, executive function, academic achievement, motor performance, neurodevelopmental disability, and health-related quality of life of children born EP since 1990; the post-surfactant era. In particular, we want to document if these outcomes are changing over time, in parallel with advances in neonatal intensive care and improving survival rates for children born EP. We will focus only on some major neurodevelopmental outcomes, but acknowledge that other outcomes such as behaviour, respiratory function, growth or general health are important, but outside the scope of the present review; however, their effects will indirectly
What is already known?

- There are many individual studies that have reported on neurodevelopmental outcomes in school-aged children who were born extremely preterm.

- Most have reported single outcomes and have come from disparate sources.

\section{What this study adds?}

- This study synthesises data from multiple sources on multiple neurodevelopmental outcomes in school-aged children who were born extremely preterm.

- The review focuses on studies from complete geographical cohorts.

- It also address the issue of whether multiple neurodevelopmental outcomes in school-aged children who were born extremely preterm are improving or not over time.

be reflected in quality of life measures, which are included in this narrative review.

\section{METHODOLOGICAL ISSUES}

The most accurate data on school-age outcomes for populations of children born EP will come from complete cohorts from defined geographical regions that capture all births. More selective cohorts, such as those derived from single hospitals or networks of hospitals, or from randomised controlled trials of specific interventions during pregnancy or after birth, have selection filters which can result in bias by excluding individuals or subgroups from whole populations who have systematically different outcomes.

Other desirable methodological issues include recruitment of contemporaneous term-born controls to compare outcomes with those born EP, to allow for different versions of test instruments and to avoid the known drift in test scores over time, known as the 'Flynn effect'. Participants should be assessed blind to knowledge of birth group. Follow-up needs to be long enough (ie, past early childhood) to determine important outcomes, and as complete as possible because those who are not followed will have higher rates of cognitive problems than those who are otherwise assessed. ${ }^{3}$ 
The Victorian Infant Collaborative Study (VICS) Group has recruited three cohorts of children born EP in the state of Victoria from three discrete eras since surfactant was introduced into clinical practice in 1991. These cohorts were born in 1991-1992, 1997 and 2005, and they have all been assessed at school-age (around 8 years of age). Each cohort has a contemporaneous control group born at term who have been assessed simultaneously by trained personnel, blinded to group allocation. We will use data from these cohorts to illustrate the extent of problems faced by children born EP when they reach school-age, and to address the issue of whether outcomes are improving or deteriorating over time. For comparable data from other regions, we will focus on studies with geographically defined cohorts who have been compared with contemporaneous controls born at term.

For individual outcomes of interest, we will also rely on recently completed systematic reviews, as identified in PubMed, rather than repeating systematic reviews ourselves, which are beyond the scope of this review.

\section{GENERAL INTELLIGENCE (IQ)}

Numerous test batteries of general intelligence or general cognitive ability can provide an estimate of IQ. In a systematic review and meta-analysis of 71 studies of children born after 1990, Twilhaar $e \mathrm{al}^{4}$ recently reported that children born either $<32$ weeks' gestation or $<1500 \mathrm{~g}$ birth weight had a standardised IQ score at 5 or more years of age of $-0.86 \mathrm{SD}(95 \% \mathrm{CI}-0.94$ to $-0.78, \mathrm{p}<0.001)$ compared with children born at term. With an SD of 15 , this translates into a mean IQ difference of -12.9 (95\% CI -14.1 to -11.7$)$. Another systematic review published in the same year comprising 44 individual studies concluded that children aged between 4 and 17 years who had been born $<32$ weeks' gestational age had an IQ of -0.82 SD $(95 \%$ CI -0.90 to -0.74) compared with controls. ${ }^{5}$ Although the latter systematic review explicitly excluded studies that selected on birth weight alone, the two reviews included many of the same studies, and hence the results are similar. Neither systematic review reported results for EP subgroups alone. Another systematic review of cognitive scores in children born preterm reported a Full Scale IQ standardised mean difference (SMD) of -0.78 (95\% CI -0.85 to -0.72$)^{6}$ in a subgroup of 2136 children born EP compared with 1829 children born at term, which translates to a mean IQ difference of -11.7 (95\% CI -12.8 to -10.8$){ }^{6}$ The latter review included a wide age range, but the mean differences were not substantially different between preterm and control groups across subgroups $2-4$ years, $4-11$ years, $11-18$ years and $>18$ years.

Data have been reported from six geographical cohort studies of children born EP or more immature after 1990 where cognitive scores at 5 or more years of age have been compared with termborn controls (table 1). ${ }^{7-10}$ The mean differences between EP and control groups from these studies are either similar to or wider than those in the systematic reviews, described previously. Moreover, proportions with intellectual impairment (IQ $<-2$ $\mathrm{SD})$ were much higher in those born EP (10\%-41\%) compared with controls $(0 \%-3 \%)$.

The differences between EP and control groups in table 1 look wider in studies outside of Australia compared with the Australian studies. This is likely due in part to the UK and Swedish EP cohorts being less mature; IQ is lower in more immature infants compared with more mature infants within the $<28$ week gestational age range. ${ }^{11}$ Also, the non-Australian studies, unlike the Australian studies, did not correct age for prematurity. Adjusting for prematurity reduces a known bias in cognitive test scores. ${ }^{12}$ For a 6 -year-old child born at 23 weeks, not adjusting for prematurity would lower a corrected IQ of 100 by approximately 8 points. Adjustment for prematurity is not mentioned in any systematic review but was probably rare among the pooled studies.

From Victorian data over three discrete eras, the mean differences in IQ between children born EP and controls within each era were similar (table 1).

\section{EXECUTIVE FUNCTION}

While children born EP have been reported to have poorer functioning than children born at term across most domains of cognition, ${ }^{13}$ executive function (EF) has been a particular focus of research. EF refers to higher-order cognitive skills necessary for completing goal-oriented activities, and includes attentional control, cognitive flexibility, reasoning ability, and planning and organisation. ${ }^{14}$

A 2009 systematic review of 12 studies containing EF data obtained at ages 7-23 years reported that working memory, cognitive flexibility and verbal fluency were all lower by 0.36 to $0.57 \mathrm{SD}$ in children born either $<34$ weeks or $<1501 \mathrm{~g}$ compared with controls. ${ }^{15}$ Data were not separately reported for the EP subgroup or at school-age only. In a subsequent systematic review and meta-analysis of 34 studies of EF at ages 4-17 years in 3701 children born $<32$ weeks' gestation, mean scores on various tests of $\mathrm{EF}$ were lower by $-0.51 \mathrm{SD}(95 \% \mathrm{CI}-0.58$ to -0.44) compared with 2921 controls. $^{5}$

The VICS group has reported the results of executive functioning rated by parents on the Behavior Rating Inventory of Executive Function at 8 years of age for 613 children born either EP or extremely low birth weight $(<1000 \mathrm{~g})$ in Victoria in 1991-1992, 1997 and 2005, and 564 contemporaneous matched controls. ${ }^{16}$ Children born EP/extremely low birth weight (ELBW; <1000g) had higher rates of executive function

Table 1 Cognitive scores of children born EP compared with controls from geographically defined cohorts from different countries

\begin{tabular}{|c|c|c|c|c|c|c|c|c|}
\hline \multirow[b]{2}{*}{ Country (reference) } & \multirow[b]{2}{*}{ Years of birth } & \multirow[b]{2}{*}{ GA (weeks) } & \multirow[b]{2}{*}{ Age assessed (years) } & \multicolumn{2}{|l|}{ IQ Mean (SD) } & \multirow{2}{*}{$\begin{array}{l}\text { Mean difference } \\
(95 \% \mathrm{Cl})\end{array}$} & \multicolumn{2}{|l|}{$<-2$ SD } \\
\hline & & & & EP & Control & & $\operatorname{EP}(\%)$ & Control (\%) \\
\hline \multirow[t]{3}{*}{ Australia $^{7}$} & 1991-1992 & $23-27$ & 8.7 & $94.9(16.5) n=198$ & $104.7(14.1) n=212$ & $-8.0(-10.9 \text { to }-5.1)^{*}$ & 14.3 & 2.7 \\
\hline & 1997 & $22-27$ & 8.4 & $93.8(14.7) n=133$ & $105.6(12.4) n=170$ & $-10.5(-13.8 \text { to }-7.1)^{*}$ & 9.9 & 1.8 \\
\hline & 2005 & $22-27$ & 7.7 & $94.7(15.7) n=137$ & $107.2(10.9) n=189$ & $-10.2(-13.3 \text { to }-7.1)^{*}$ & 13.6 & 0 \\
\hline UK and Ireland ${ }^{8}$ & 1995 & $22-25$ & $6.3+$ & $82.1(19.2) n=241$ & $105.7(11.8) n=160$ & $-24.0(-27$ to -20$)$ & 40.7 & 1.3 \\
\hline France $^{9}$ & 1997 & $24-27$ & $5 t$ & $90.0(18.7) n=223$ & $106.4(17.8) n=320$ & $-16.4(-17.9$ to -14.8$)$ & 17.9 & 3.4 \\
\hline Sweden ${ }^{10}$ & $2004-2007$ & $22-26$ & $6.6+$ & $83.4(14.8) n=371$ & $100.3(11.7) n=367$ & $-14.2(-16.3 \text { to }-12.1)^{*}$ & 32.1 & 2.2 \\
\hline
\end{tabular}

${ }^{*}$ Adjusted for sociodemographic variables.

†Age not corrected for prematurity.

$E P$, extremely preterm; GA, gestational age. 
Table 2 Academic achievement at 8 years for extremely preterm and control groups born in the state of Victoria, contrasted over different eras

\begin{tabular}{|c|c|c|c|c|c|c|}
\hline \multirow[b]{3}{*}{ Outcomes } & \multicolumn{6}{|c|}{ Birth years } \\
\hline & \multicolumn{2}{|c|}{ 1991-1992 } & \multicolumn{2}{|c|}{1997} & \multicolumn{2}{|c|}{2005} \\
\hline & EP & Control & EP & Control & EP & Control \\
\hline Mean difference $(95 \% \mathrm{Cl})^{*}$ & $-5.5(-8.5$ to -2.4$)$ & & $-8.1(-11.8$ to -4.5$)$ & & $-12.3(-16.0$ to -8.5$)$ & \\
\hline Spelling & $93.8(12.9) n=199$ & $99.7(13.2) n=210$ & $96.4(16.0) n=134$ & $104.2(14.5) n=168$ & $93.9(17.6) n=138$ & $108.6(15.2) n=188$ \\
\hline Mean difference $(95 \% \mathrm{Cl})^{*}$ & $-4.8(-7.3$ to -2.3$)$ & & $-7.7(-11.3$ to -4.1$)$ & & $-12.0(-15.9$ to -8.2$)$ & \\
\hline
\end{tabular}

*Allowing for clustering for multiple births, and adjusted for age of the child at assessment, mother's age at birth of the child and sociodemographic variables.

$E P$, extremely preterm.

problems compared with controls, but the differences were greatest between EP/ELBW and control groups for the 2005 cohort. Within specific domains, the 2005 cohort had particular problems with working memory, and planning and organisation. Poorer EF in children born EP/ELBW persisted into adolescence (mean age 17 years) for the those born in 1991-1992 compared with controls; at 17 years, they had worse functioning in verbal processing speed, attentional control, cognitive flexibility and goal-setting (effect sizes, -0.7 to $-0.2 \mathrm{SD}) .{ }^{17}$ In the same cohort, persistence of EF difficulties from early school-age to adolescence in children born EP/ELBW was associated with poorer academic achievement in adolescence. ${ }^{18}$

\section{ACADEMIC ACHIEVEMENT}

In a systematic review of 17 studies comparing 2390 children born preterm with 1549 controls where children were at least 5 years of age, preterm children had lower scores for arithmetic (SMD -0.71), reading (SMD -0.44) and spelling (SMD -0.52), but results were not reported for children born EP alone. ${ }^{19}$ With a SD of 15 , these differences convert to -10.6 for arithmetic, -6.6 for reading and -7.8 for spelling.

The VICS group have reported academic achievement at 8 years of the three discrete cohorts of children born EP and controls, described previously. ${ }^{7}$ Not only do children born EP have poorer performance on tests of academic achievement than do controls born at term, the gap is widening over time (table 2). Moreover, the mean differences for the Victorian cohort born in 2005 well exceed those in the systematic review. For example, the Victorian children born EP in 2005 performed -0.8 SD lower than term controls on tests of reading, spelling and mathematics, with rates of specific learning difficulties $(<-2$ SD) ranging from $14 \%$ for spelling to $23 \%$ for mathematics. Not surprisingly, children born EP are more likely to need educational remediation and repeat grades in school. ${ }^{20}$

\section{MOTOR FUNCTION}

\section{Cerebral palsy (CP)}

Rates of CP in the three Victorian cohorts of children born EP at 8 years of age were 13\% for 1991-1992, 11\% for 1997 and $14 \%$ for $2005 .^{7}$ Rates of CP in school-age survivors born EP from other geographical regions are similar to those reported in Victoria, as follows: UK/Ireland ${ }^{8}-15 \%$ at 6 years for survivors $<26$ weeks' gestation born in 1995; France ${ }^{9}-10 \%$ at 5 years for survivors <28 weeks' gestation born in 1997; Sweden ${ }^{10}$ $10 \%$ at 6.5 years for survivors $<27$ weeks' gestation born in 2004-2007. In the Victorian CP Register, which includes nearly all children in Victoria with CP aged 5 years or older rates of CP are decreasing over time in children born $<28$ weeks, from $10 \%$ for births in 1995-1997, 10\% for 1998-2000, 9\% for 2001-03,
$7 \%$ for 2004-2006 and 6\% for births in 2007-2009, ${ }^{21}$ the latter rates being substantially lower than what VICS reported for births in 2005 .

\section{Non-CP motor impairment}

Non-CP motor impairment in very preterm children has been systematically reviewed on several occasions. De Kieviet et $a l^{22}$ reported that mean scores on standardised motor tests were up to 0.65 SD lower in children born $<33$ weeks' gestation or $<1501 \mathrm{~g}$ birth weight at school age compared with controls. Williams et $a l^{23}$ reported a pooled estimate for mild-moderate non-CP motor impairment in children born preterm of $40 \%$, and for moderate motor impairment a rate of $19 \%$. Neither systematic review reported results for children born EP only.

For the Victorian cohorts of births in 1991-1992, 1997 and 2005, Spittle et $a l^{24}$ reported that motor impairment at school-age for children born EP/ELBW was substantially worse than in contemporaneous controls, and that the gap was widening over time between cohorts. Since the rates of CP were relatively stable over time, as described previously, the deterioration in motor function resulted from an increase in non-CP motor impairment in survivors born EP/ELBW, from 13\% in $1991-1992$, to $15 \%$ in 1997 , and to $26 \%$ in 2005 . While the reasons for this increase in so-called 'milder' motor impairments are unknown, motor competence of children is decreasing globally as a result of increased sedentary behaviour and reductions in physical activity over time. ${ }^{25}$

\section{MAJOR NEURODEVELOPMENTAL DISABILITY}

Combining some of the previous outcomes, the overall rates of major neurodevelopmental disability at school-age, generally defined as any of an IQ $<-2$ SD, CP that is more than just mild, blindness or deafness in six geographical cohorts are shown in table $3 .^{7-10}$ To parents, these outcomes translate into substantial problems for their child with thinking, walking, talking, seeing or hearing, and range from approximately 1 -in-5 to 2 -in-5. These rates cannot be interpreted fully without understanding that 1-in-50 to 2-in-50 controls born at term also have these problems.

\section{HEALTH-RELATED QUALITY OF LIFE}

Zwicker and Harris ${ }^{26}$ systematically reviewed studies reporting health-related quality of life (HRQOL) from infancy to early adulthood, reporting that HRQOL was worse in children born preterm or very low birth weight than controls when they were younger, but differences between the groups diminished with age. The review contained only one study when children were 8 years of age, and four studies of teenagers between 12 and 16 
Table 3 Major neurodevelopmental disability at school-age in children born EP and at term compared across geographically defined cohorts from different countries

\begin{tabular}{|c|c|c|c|c|}
\hline \multirow[b]{2}{*}{ Country (reference) } & \multirow[b]{2}{*}{ Years of birth } & \multirow[b]{2}{*}{ Gestational age (weeks) } & \multicolumn{2}{|l|}{ Major disability } \\
\hline & & & Preterm & Control \\
\hline \multirow[t]{2}{*}{ Australia $^{7}$} & 1991-1992 & $23-27$ & $38 / 210(18 \%)$ & $6 / 213(3 \%)$ \\
\hline & 2005 & $22-27$ & $26 / 147(18 \%)$ & $1 / 189(0.5 \%)$ \\
\hline UK and Ireland ${ }^{8}$ & 1995 & $22-25$ & $110 / 241(46 \%)$ & $2 / 160(1 \%)$ \\
\hline France $^{9}$ & 1997 & $24-28$ & $90 / 402(22 \%)$ & $12 / 320(4 \%)$ \\
\hline
\end{tabular}

Major neurodevelopmental disability defined in the Victorian studies as any of moderate or severe cerebral palsy (unable to walk, or walking with considerable difficulty, with or without appliances, or GMFCS levels 2-5), blindness, deafness or an IQ $<-2$ SD. Other cohorts had similar criteria except the studies from the UK and Ireland, and from Sweden included less severe vision loss than blindness.

EP, extremely preterm.

years of age; the other studies included in the review were either preschool-age $(<5$ years) or young adults $(18$ or more years of age). They did not report differences specifically for children born EP at school-age compared with controls.

In the first school-age report of quality of life, Saigal et $a l^{27}$ studied 156 8-year-olds who were born between 1977 and 1982 weighing $<1001 \mathrm{~g}$, and 145 controls. Utilities were obtained from community preference values for various health states. Children born $<1001 \mathrm{~g}$ had lower overall utility scores as well as more limitations in cognition, sensation, mobility and selfcare than did controls, but not in emotion or pain. Gire et $a^{28}$ reported that HRQOL of 3018 -year-old children born $<28$ weeks' gestation in 2004-2007 and free of major disabilities was worse than that in the French population as a whole. Interestingly, children born EP identified more problems with relationships with friends, self-esteem and leisure than did control children, whereas parents of children born EP identified more problems with psychological well-being, schoolwork and vitality than did parents of controls.

HRQOL at 8 years of age in 475 children born EP in the state of Victoria was compared with 570 contemporaneous term-born controls over the three eras 1991-1992, 1997 and 2005. ${ }^{29}$ In all eras, parent-reported median utilities were lower by more than 0.05 for children born EP compared with controls, a clinically important difference on a scale that ranges from 1 for perfect health to 0 for death. Mean differences (MDs) between EP children and matched controls within each era were lower in the 2005 cohort compared with both the 1991-1992 cohort (MD $-0.054,95 \% \mathrm{CI}-0.097$ to -0.010 ) and the 1997 cohort (MD $-0.053,95 \% \mathrm{CI}-0.097$ to -0.009 ), which suggests that parentreported HRQOL may be deteriorating over time.

Findings are more variable when assessing HRQOL in adolescents and young adults born preterm or low birth weight; results have been synthesised in several different reviews. ${ }^{26}{ }^{30}$ At these older ages, most studies report no substantial differences in HRQOL between those born preterm or low birth weight and controls, particularly if the participant was reporting on their own HRQOL. Although the Victorian cohort born EP in 19911992 cohort had lower utility scores than controls at 8 years on parental report, when they were 18 years of age their HRQOL on self-report was similar to controls. ${ }^{31}$

\section{CLINICAL IMPLICATIONS}

An understanding of the range of outcomes at school-age for children born EP will help clinicians and families when making decisions about care at critical timepoints. An early timepoint is typically around the time of birth, when knowledge of long-term problems may influence a decision to not embark on intensive care for an infant born EP. There may be other potentially lifechanging events that occur during the newborn hospital stay where decisions to cease intensive care might arise. Organising the transition to home, including providing early intervention both in the nursery and after discharge home is informed by knowledge of the various school-age outcomes that are possible.

Although CP may be decreasing in infants born $\mathrm{EP}^{21}$ it is important for clinicians to be aware that other motor impairments can have a substantial impact on a child at school age and on their family's function. Children with milder challenges at school age are the ones who are often missed, or who have diagnoses delayed, and hence struggle to access assistance. Clinicians need to remember that the school-age problems that they would like to avoid most for the child, such as CP or intellectual impairment, may not be the problems that might concern the parents or the child themselves; the latter groups might be more concerned with future happiness and peer relationships, for example, rather than more specific medically-defined impairments.

Understanding a range of important school-age outcomes can help to target interventions more specifically. They are also important endpoints to consider for monitoring the effectiveness of interventions, particularly from randomised controlled trials. However, obtaining funding for school-age outcomes for perinatal trials is difficult because of the long time frame involved. Increasingly, the importance of choosing the most important outcomes for the child and their family is being recognised. Rather than using traditional measures of cognitive and motor development such as rates of intellectual impairment and CP as end points of trials, outcomes such as quality of life and well-being may be considered. Many interventions may not be able to change a diagnosis, such as $\mathrm{CP}$ or autism spectrum disorder, but can still improve the functional outcomes for these children, resulting in better peerfriendships or increased participation in physical activity. Involving consumers, both children born EP and their families, in the design of research trials from the beginning will ensure research is focused on improving outcomes that are meaningful for both clinicians and the families and children themselves.

Because the rates of adverse outcomes at school-age are too high in children born EP, and particularly since some outcomes may be deteriorating rather than improving over time, ${ }^{71624}$ strategies before, during and after birth, including after discharge home, through infancy and into school-age to ameliorate these problems must be developed. Financial support for new trials may require separate grant applications, but we must persist to optimise the outcomes for our most vulnerable children and their families. 
Correction notice This article has been amended since it was published online. In the previous version, in table 1, the upper confidence intervals for mean differences all lost their minus signs. The article has since been corrected.

Contributors LWD conceived and designed the study, and drafted and revised the article. AS, PJA and JLYC conceived and designed the study, and revised the article. All authors approved the final manuscript as submitted.

Funding Supported by grants from the National Health and Medical Research Council of Australia (Centre of Clinical Research Excellence \#546519; Centres of Research Excellence \#1060733 and \#1153176; Project Grant \#108702, Leadership Fellowship \#1176077 to PJA), Medical Research Future Fund (Career Development Fellowship \#1141354 to JC) and the Victorian Government's Operational Infrastructure Support Program.

Competing interests None declared.

Patient consent for publication Not required.

Provenance and peer review Commissioned; externally peer reviewed.

Data availability statement No data are available. There are no data available relevant to this review.

\section{ORCID iDs}

Lex W Doyle http://orcid.org/0000-0002-7667-7312

Jeanie Ling Yoong Cheong http://orcid.org/0000-0001-5901-0455

\section{REFERENCES}

1 Cheong JLY, Olsen JE, Huang L, et al. Changing consumption of resources for respiratory support and short-term outcomes in four consecutive geographical cohorts of infants born extremely preterm over 25 years since the early 1990s. BMJ Open 2020:10:e037507.

2 Hack M, Taylor HG, Drotar D, et al. Poor predictive validity of the Bayley scales of infant development for cognitive function of extremely low birth weight children at school age. Pediatrics 2005;116:333-41.

3 Callanan C, Doyle L, Rickards A, et al. Children followed with difficulty: how do they differ? J Paediatr Child Health 2001;37:152-6.

4 Twilhaar ES, Wade RM, de Kieviet JF, et al. Cognitive outcomes of children born extremely or very preterm since the 1990s and associated risk factors: a meta-analysis and meta-regression. JAMA Pediatr 2018;172:361-7.

5 Brydges CR, Landes JK, Reid CL, et al. Cognitive outcomes in children and adolescents born very preterm: a meta-analysis. Dev Med Child Neurol 2018;60:452-68.

6 Allotey J, Zamora J, Cheong-See F, et al. Cognitive, motor, behavioural and academic performances of children born preterm: a meta-analysis and systematic review involving 64061 children. BJOG 2018:125:16-25.

7 Cheong JLY, Anderson PJ, Burnett AC, et al. Changing neurodevelopment at 8 years in children born extremely preterm since the 1990s. Pediatrics 2017;139:e20164086.

8 Marlow N, Wolke D, Bracewell MA, et al. Neurologic and developmental disability at six years of age after extremely preterm birth. N Engl J Med 2005;352:9-19.

9 Larroque B, Ancel P-Y, Marret S, et al. Neurodevelopmental disabilities and special care of 5-year-old children born before 33 weeks of gestation (the EPIPAGE study): a longitudinal cohort study. Lancet 2008;371:813-20.

10 Serenius F, Ewald U, Faroogi A, et al. Neurodevelopmental outcomes among extremely preterm infants 6.5 years after active perinatal care in Sweden. JAMA Pediatr 2016;170:954-63
11 Joseph RM, O'Shea TM, Allred EN, et al. Neurocognitive and academic outcomes at age 10 years of extremely preterm newborns. Pediatrics 2016;137. doi:10.1542/ peds.2015-4343. [Epub ahead of print: 22 Mar 2016].

12 Wilson-Ching M, Pascoe L, Doyle LW, et al. Effects of correcting for prematurity on cognitive test scores in childhood. J Paediatr Child Health 2014;50:182-8.

13 Anderson PJ. Neuropsychological outcomes of children born very preterm. Semin Fetal Neonatal Med 2014;19:90-6.

14 Anderson P. Assessment and development of executive function (EF) during childhood. Child Neuropsychol 2002;8:71-82.

15 Aarnoudse-Moens CSH, Weisglas-Kuperus N, van Goudoever JB, et al. Meta-analysis of neurobehavioral outcomes in very preterm and/or very low birth weight children. Pediatrics 2009;124:717-28.

16 Burnett AC, Anderson PJ, Lee KJ, et al. Trends in executive functioning in extremely preterm children across 3 birth eras. Pediatrics 2018;141:e20171958.

17 Burnett AC, Scratch SE, Lee KJ, et al. Executive function in adolescents born $<1000 \mathrm{~g}$ or <28 weeks: a prospective cohort study. Pediatrics 2015;135:e826-34.

18 Costa DS, Miranda DM, Burnett AC, et al. Executive function and academic outcomes in children who were extremely preterm. Pediatrics 2017;140.

19 Twilhaar ES, de Kieviet JF, Aarnoudse-Moens CS, et al. Academic performance of children born preterm: a meta-analysis and meta-regression. Arch Dis Child Fetal Neonatal Ed 2018;103:F322-30.

20 Anderson P, Doyle LW, Victorian Infant Collaborative Study Group. Neurobehavioral outcomes of school-age children born extremely low birth weight or very preterm in the 1990s. JAMA 2003;289:3264-72

21 Galea C, Mcintyre S, Smithers-Sheedy H, et al. Cerebral palsy trends in Australia (1995-2009): a population-based observational study. Dev Med Child Neurol 2019;61:186-93

22 de Kieviet JF, Piek JP, Aarnoudse-Moens CS, et al. Motor development in very preterm and very low-birth-weight children from birth to adolescence: a meta-analysis. JAMA 2009;302:2235-42.

23 Williams J, Lee KJ, Anderson PJ. Prevalence of motor-skill impairment in preterm children who do not develop cerebral palsy: a systematic review. Dev Med Child Neurol 2010;52:232-7.

24 Spittle AJ, Cameron K, Doyle LW, et al. Motor impairment trends in extremely preterm children: 1991-2005. Pediatrics 2018;141:e20173410.

25 Bardid F, Rudd JR, Lenoir M, et al. Cross-cultural comparison of motor competence in children from Australia and Belgium. Front Psychol 2015;6:964.

26 Zwicker JG, Harris SR. Quality of life of formerly preterm and very low birth weight infants from preschool age to adulthood: a systematic review. Pediatrics 2008;121:e366-76

27 Saigal S, Feeny D, Furlong W, et al. Comparison of the health-related quality of life of extremely low birth weight children and a reference group of children at age eight years. J Pediatr 1994:125:418-25.

28 Gire C, Resseguier N, Brévaut-Malaty V, et al. Quality of life of extremely preterm school-age children without major handicap: a cross-sectional observational study. Arch Dis Child 2019;104:333-9.

29 Peart S, Cheong JLY, Roberts G. Changes over time in quality of life of school-aged children born extremely preterm: 1991 to 2005. Arch Dis Child Fetal Neonatal Ed 2021. doi:10.1136/archdischild-2020-320582. [Epub ahead of print: 17 Feb 2021].

30 van der Pal S, Steinhof M, Grevinga M, et al. Quality of life of adults born very preterm or very low birth weight: a systematic review. Acta Paediatr 2020;109:1974-1988.

31 Roberts $\mathrm{G}$, Burnett $\mathrm{AC}$, Lee $\mathrm{KJ}$, et al. Quality of life at age 18 years after extremely preterm birth in the post-surfactant era. J Pediatr 2013;163:1008-13. 